\title{
Spinal cord vascular shunts: spinal cord vascular malformations and dural arteriovenous fistulas
}

\author{
Leodante da Costa, M.D., ${ }^{1,3}$ Amir R. Dehdashti, M.D., ${ }^{2}$ and Karel G. terBrugge, M.D. ${ }^{3}$ \\ ${ }^{1}$ Division of Neurosurgery, Department of Surgery, Sunnybrook Health Sciences Centre, \\ University of Toronto, Canada; and ${ }^{2}$ Division of Neurosurgery, Department of Surgery \\ and ${ }^{3}$ Department of Medical Imaging, Toronto Western Hospital, University of Toronto, Canada
}

\begin{abstract}
Object. Spinal cord vascular malformations are rare, fascinating lesions. In this paper, the authors' goal was to demonstrate how these lesions, more specifically spinal cord arteriovenous malformations and dural arteriovenous fistulas, are assessed, classified, and managed at their institution. They also highlight some aspects of classification and management that may be different from the views of others.

Methods. The authors reviewed the 20-year experience at the senior author's institution regarding the management of spinal cord vascular malformations. They discuss the management, surgical and endovascular treatment results, and the classification that resulted from the combined experience of 3 major reference centers.

Results. The accumulated knowledge on embryological and pathophysiological aspects in such a rare disease resulted in a more global, patient-oriented (and not radiologically oriented) approach to spinal cord shunts.

Conclusions. The multiple classifications proposed for spinal cord vascular malformations reflect the continuous advancement of the authors' understanding. They adopt a classification based on new physiological and genetic data that treats these lesions as expressions of more complex disease processes and not simply a morphological target, with direct impact on therapeutic options. (DOI: 10.3171/FOC.2009.26.1.E6)
\end{abstract}

KEY WORDS $\bullet$ spinal arteriovenous malformation $\bullet$
spinal dural arteriovenous fistula $\bullet$ spinal vascular malformation

$\mathrm{T}$ HE first clinical description of a spinal vascular malformation was in 1890 by Berenbruch, ${ }^{10}$ who did not recognize the lesion as a vascular entity at surgery but only later at autopsy. Two decades later, Krause $^{32}$ recognized a spinal vascular malformation at surgery. Credit for first recognizing that spinal vascular malformations can cause SAH must be given to Heboldt in $1885^{28}$ and Gaupp in $1888,{ }^{23}$ who referred to these lesions as "hemorrhoids of the pia mater." Since then, multiple eponyms and classifications have been used for the various types of vascular malformations of the spine and spinal cord. Although reflecting the continuous evolution in our understanding of the subject, the many classifications and variable nomenclature attest to our difficulty in understanding and comparing them. In 1943, WyburnMason $^{57}$ recognized 2 main types of spinal vascular lesions: the venous type, consisting of an abnormal mass of sinuous, turgid, blue, pial veins, usually located posteriorly and below the midthoracic region of the cord;

\footnotetext{
Abbreviations used in this paper: ASA = anterior spinal artery; $\mathrm{AVF}=$ arteriovenous fistula; $\mathrm{DAVF}=$ dural $\mathrm{AVF} ; \mathrm{NBCA}=$ $N$-butyl-2-cyanoacrylate; $\mathrm{SAH}=$ subarachnoid hemorrhage.
}

and the arteriovenous type, consisting of a fistulous capillary bed, preferentially located in the cervical enlargement anteriorly or at the lumbar enlargement, indicating for the first time that true medullary AVMs are different from what we know today as spinal dural fistulas.

The introduction of selective spinal angiography in the late 1960s and early 1970s and the studies of large series of patients by Houdart, ${ }^{30}$ Di Chiro, ${ }^{15}$ Baker, ${ }^{6}$ Djindjian, ${ }^{16-18}$ and their colleagues further improved our anatomical and hemodynamic understanding of those rare lesions. Aminoff and colleagues ${ }^{3-5}$ later extensively reviewed the pathophysiology, clinical presentation, and prognosis of vascular malformations of the spinal cord. Confusion was propagated by attempts to classify spinal AVMs based on morphological aspects. ${ }^{31,42,51}$ From an anatomical point of view, we prefer to distinguish paraspinal (including vertebral/vertebral) and epidural locations from dural and intradural locations of the AVM or AVF, realizing that the neurological symptoms will nearly always be related to the venous drainage pattern of the lesion no matter where the nidus is situated.

Vascular malformations of the spine and spinal cord are considered uncommon lesions, representing 3-16\% 


\section{Da Costa, A. R. Dehdashti, and K. G. terBrugge}

of all spinal space-occupying lesions. ${ }^{39,41,54,57}$ Dural AVFs are more common than spinal cord AVMs, the latter of which have an incidence of $\sim 10 \%$ that of brain AVMs. ${ }^{14,47}$ In this article, we aim to demonstrate the way spinal AVMs, specifically spinal cord AVMs and spinal DAVFs, are assessed, classified, and managed at our institution, highlighting some aspects of classification and management that may be different from the views of others.

\section{Spinal Cord AVMs}

This group of arteriovenous shunts includes intradural lesions supplied by branches of the radicular arteries that follow the ventral (radiculomedullary or anterior spinal arteries) or the dorsal nerve roots (radiculo-pial or posterior spinal arteries). This includes AVMs located along the intradural portion of the spinal nerves and the terminal filum. The lesions may be located along the surface of the cord (perimedullary), may be intramedullary, or both. They can be further classified into direct AVFs (macro- or microfistulas), representing $\sim 20 \%$ of the cases, invariably located in the surface of the cord, and true nidal types of AVMs (80\% of spinal cord AVMs) with an (at least partially) intramedullary nidus (Fig. 1). Multiplicity of shunts, with obvious therapeutic implications, is found in up to $20 \%$. Syndromes associated with spinal vascular malformations are also included in this group, such as the spinal arteriovenous metameric, Klippel-Trenaunay, or Parkes-Weber syndromes.

Several classifications have been proposed,7,26,29,42,51 dividing the AVMs into subgroups based on morphological data. Based on angiographic interpretations that can be subjective and the relationship of the shunt with anatomical compartments of the vertebral column and spinal cord, these classifications lump together dural fistulas and true spinal cord AVMs, and sometimes even spinal tumors. The classifications assume that the lesions are frozen static in time and are not dynamic entities capable of change and subjected to genetic, hemodynamic, and biological influences. The permanent connection of a lesion to a treatment option solely on its placement in a given category is probably unwise, considering the continuous evolution of our understanding of vascular anatomy of the spinal cord, spinal cord arteriovenous shunts, and improvements in treatment tools and materials. ${ }^{11,43,48}$ Rather, we adopt a classification that considers the supposed origin of each shunt, its angioarchitecture, and acknowledges the concept of "host" and the relationship between the malformation and the spinal cord itself, ${ }^{45}$ with the knowledge that changes in this equilibrium may lead to changes in the clinical picture and prognosis.

We classify spinal cord arteriovenous shunts into 3 broad groups: those that are part of genetic hereditary disorders, those that are genetic but a nonhereditary disorder, and those with isolated focal lesions. The first group (genetic hereditary lesions) is represented by hereditary hemorrhage telangiectasia (Rendu-Osler-Weber syndrome) in which single shunt fistulas are present due to the compromise of vascular cells at the germinal stage. The second group (genetic nonhereditary lesions) involves multiple shunts that, although they are not related

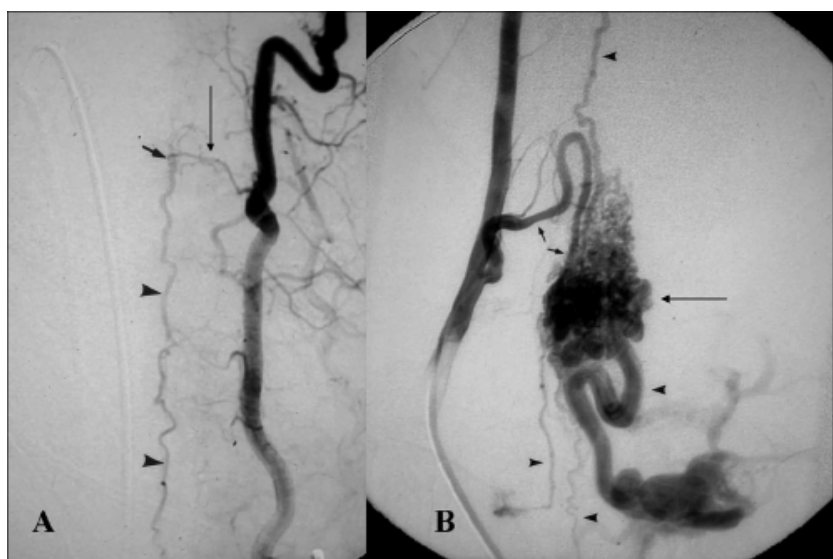

FIG. 1. Angiograms. A: The ventral perimedullary cervical microfistula (short arrow) is fed by the radiculomedullary artery (long arrow) and drains into the ventral perimedullary vein (arrowheads). B: An intramedullary cervical spinal cord AVM (long arrow). The nidus is supplied by radiculomedullary artery (the ASA; short arrows) and drains into the perimedullary and radicular veins (arrowheads).

to a hereditary disorder, may share metameric links. In this group, cells are affected very early in their biological and/or embryonic life, and all organs to which these cells migrate in the future may harbor the malformations. A clear metameric disposition can be demonstrated (Cobb syndrome) or strongly suspected. The third group (focal lesions) includes single lesions, either AVMs or microfistulas, in which a genetic component cannot be shown. ${ }^{45}$ In our experience with children, the phenotype of a spinal cord AVM is nearly always an AVF; the nidus type of AVMs is more prevalent during the 2 nd and 3rd decades of life. As one can already suspect, management may be completely different for each group (an AVM in a patient with a systemic vascular compromise will be very different from an isolated focal AVM and requires a different decision-making process in management). We believe that this classification places the spinal cord AVM into a broader context, taking into consideration new physiological and genetic data, treating these lesions as expressions of more complex disease processes that may not be completely evident on imaging alone and may not simply be a morphological target. Management is then chosen based on the characteristics of each lesion and not simply by its placement in a given category.

Spinal cord AVMs usually present in the 3rd decade of life, but they can be diagnosed in children $<16$ years old in $20 \%$ of the cases. ${ }^{58}$ When the pediatric population is included, a male predominance is shown, but no sex predominance is found in the adult population. ${ }^{44,45} \mathrm{Hem}-$ orrhage is the most common presentation, ${ }^{5,11}$ occurring in $50 \%$ of all patients with spinal cord AVMs, and it is often associated with sudden onset of new neurological deficits or with worsening of preexisting deficits. ${ }^{5,19,48,58}$ The typical syndrome of spinal hemorrhage is characterized by acute severe back pain spreading along the spinal axis and legs. Motor and sensory symptoms and bladder and bowel dysfunction can occur. In a small percentage of patients $(25 \%)$, preexisting spinal cord or nerve root symptoms is present. Intracranial SAH can occur with se- 


\section{Spinal cord vascular shunts}

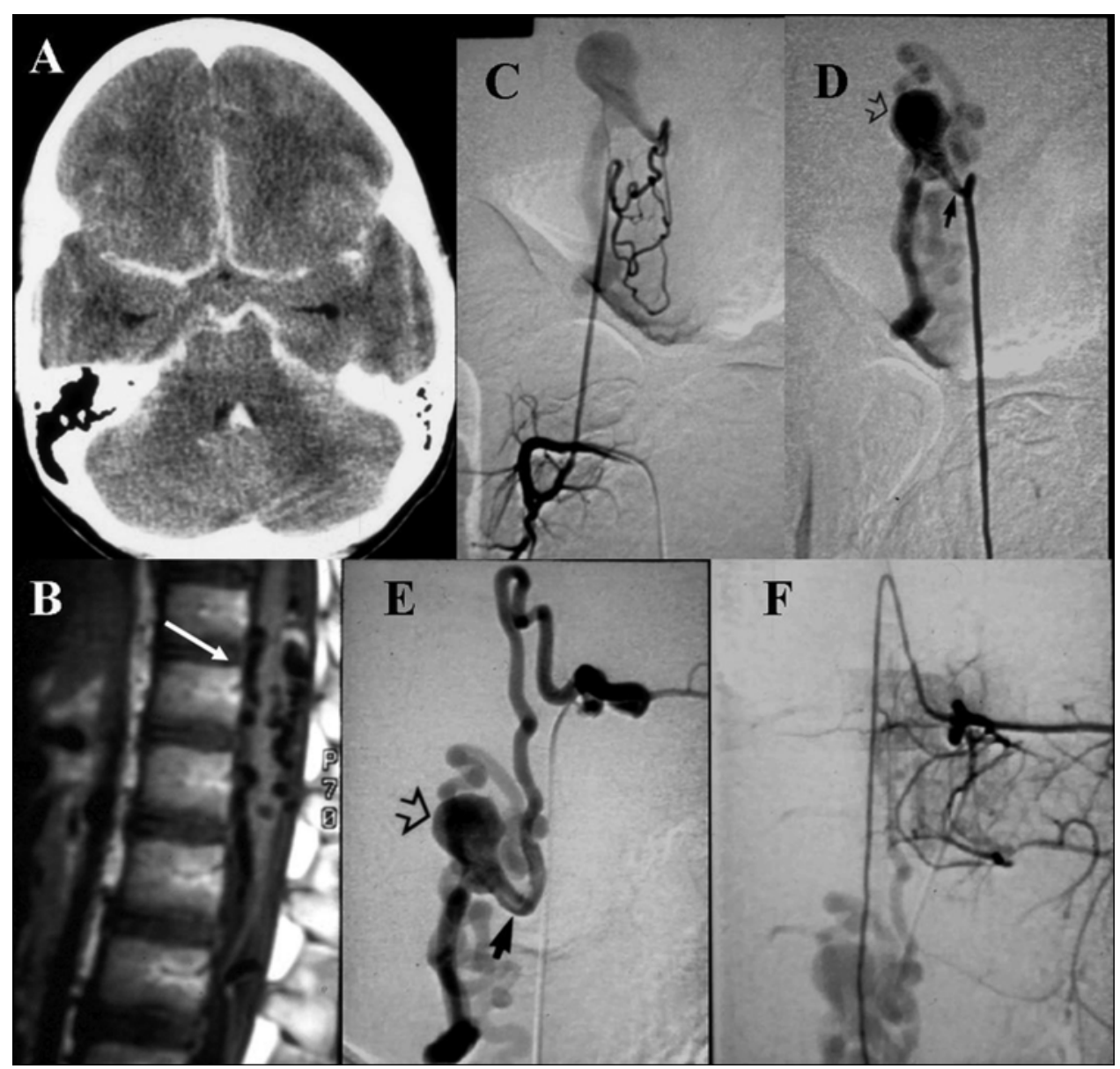

FIG. 2. Images obtained in a young boy presenting with multiple episodes of SAH. Multiple cerebral angiograms revealed no findings. A: A contrast-enhanced CT scan showing SAH and intraventricular blood. B: Sagittal T1-weighted MR image obtained after sudden onset of back pain, demonstrating thoracic intradural flow voids (arrow). C-F: Spinal angiograms demonstrating a dorsal perimedullary spinal cord AVF (small black arrow) supplied by right (C) and left (D) lumbar radiculo-pial (posterior spinal) arteries as well as the left thoracic radiculo-pial artery (E) and without direct supply from radiculomedullary (anterior spinal) arterial system (F), draining into an enlarged dorsal perimedullary venous system (open arrow in D and E).

vere headaches and disturbance of consciousness, and an intracranial origin can be wrongly suspected (Fig. 2). The natural history is based on small series that may include different lesions, but these are thought to be severe lesions with a rebleeding rate of nearly $10 \%$ in the 1st month and $40 \%$ in 1 year. ${ }^{3-5}$ The hemorrhage rate seems to be different in the pediatric population in which hemorrhage and hematomyelia are more frequent. ${ }^{44,49}$ Nonhemorrhagic symptoms include root or back pain, weakness, sensory changes, sexual, bowel, and bladder dysfunction, and rarely a bruit.

Computed tomography scanning and myelography no longer have a significant role in the initial screening of suspected spinal cord AVMs. Magnetic resonance imaging is the initial imaging modality of choice when a vascular pathological entity of the spinal cord is suspected. The T2-weighted images are useful for small lesions with slow flow. Axial T1-weighted imaging slices show areas of low signal intensity in the center of the cord, with high signal on T2-weighted images. Magnetic resonance imaging studies may be needed to accurately localize the lesion in relation to the cord tissue and the meningeal spaces, and MR imaging may also be useful in identifying spinal cord hemorrhage, thrombosis, intramedullary cavities, or atrophy, demonstrating extraspinal extension of the spinal arteriovenous metameric syndromes and distant signal changes that may explain otherwise confusing neurological symptoms.

Angiography of the spine remains the gold standard in the diagnosis and treatment planning of vascular lesions of the spine and spinal cord. Different institutions use different angiography protocols, but we favor selective angiography with a territorial approach, performed after induction of general anesthesia with controlled respiration. The angiographic investigation must outline the normal vasculature around the disease, ensuring that the full extent of the lesion is visualized and its effect on the spinal cord is understood to allow for proper treatment planning. Differentiation of the primary malformation from acquired features reflecting the arterial or venous response to the AVM over time is of utmost importance. Aspects to be observed in superselective angiography are arterial features such as peri- and intramedullary anastomosis, direct and indirect AVM supply (which may repre- 


\section{Da Costa, A. R. Dehdashti, and K. G. terBrugge}

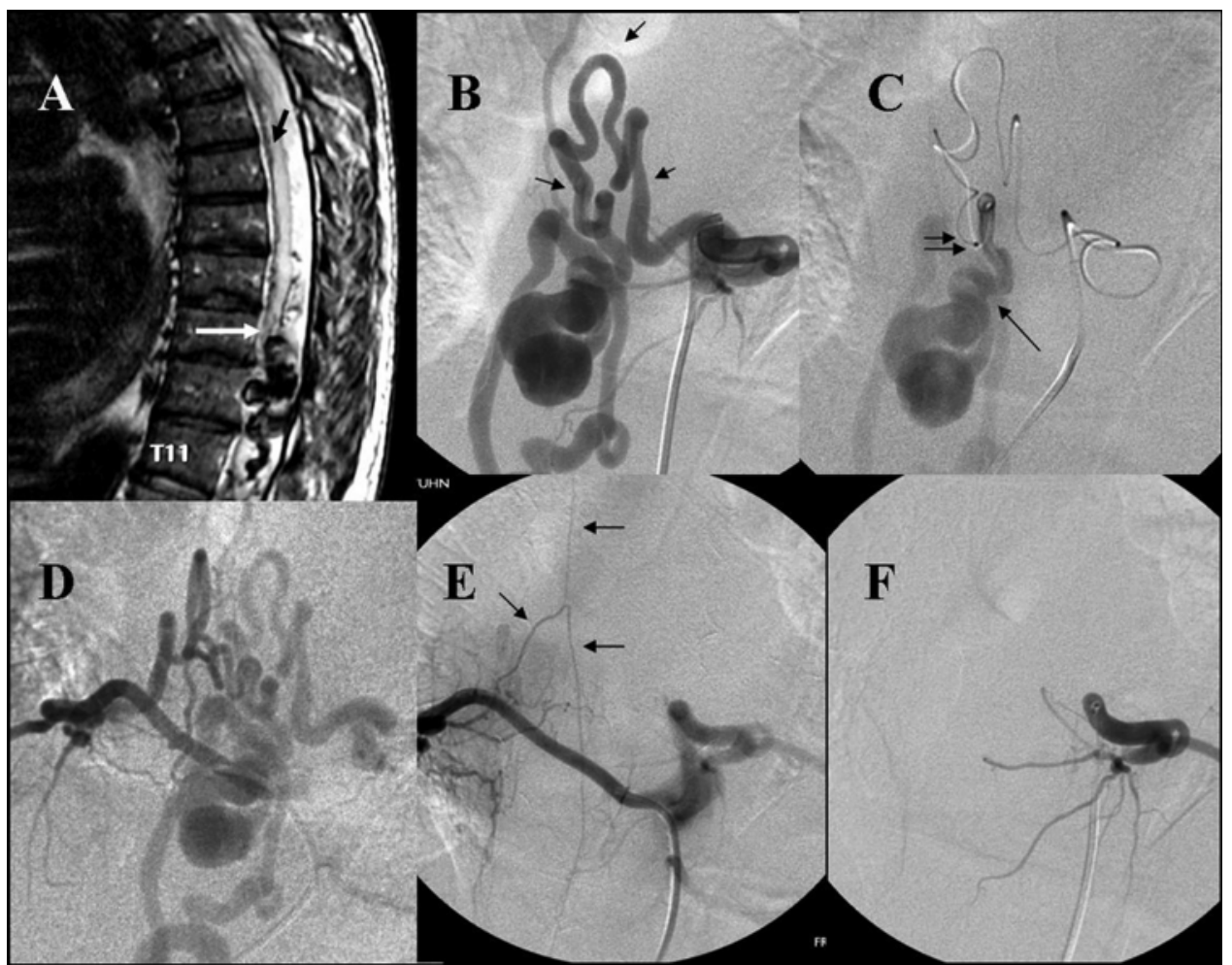

FIG. 3. Images obtained in a middle-aged man with a slowly progressive neurological deficit. A: A T2-weighted MR image showing edema within the spinal cord (black arrow) as well as multiple intradural flow voids (white arrow). B: A spinal angiogram demonstrating a high-flow dorsally located perimedullary AVF supplied by the left T-9 intercostal/radicular posterior spinal artery (arrows). C: During superselective catheterization the tip of microcatheter (double arrows) was positioned just proximal to the fistulas point (single arrow), and pure NBCA was injected without complication. D and E: Injection of the contralateral intercostal artery (right T-9), which had shown participation in the AVF prior to embolization (D), demonstrating complete cure of the AVF with preservation of anterior spinal artery at that level (arrows in E). F: Postembolization left T-9 injection showing no filling of spinal AVF. The patient made an excellent neurological recovery.

sent the "sump" effect and collateral recruitment), associated aneurysms and pseudoaneurysms, venous drainage, and most important, spinal cord supply. The nidus arrangement is difficult to appreciate at the cord level due to the complex axial and longitudinal anastomosis and the presence of sulcal perforating vessels. The situation of the venous drainage should be evaluated given that venous hypertension or thrombosis can be associated with progressive neurological deterioration, mimicking spinal dural DAVFs, or hemorrhage. Venous thrombosis responsible for clinical symptoms may be suspected on angiography but is best demonstrated on MR imaging.

The goal in the management of spinal cord AVMs is to preserve neurological function and not to obtain a perfect radiological picture. Cure of these lesions is seldom obtained without morbidity. Partial targeted treatment to obliterate weak portions like arterial or nidal aneurysms, size reduction, decreased flow, and decongestion of the venous drainage may improve a clinical situation or modify the natural history, and in our experience may represent a better choice than aggressive treatment aimed at total obliteration of the AVM. The treatment plan should consider the patient's age, the clinical presentation (single or multiple hemorrhages), the morphology (associated aneurysms or venous varix), and flow (impaired venous drainage or stagnation) of the lesion. Ideally of course all symptomatic lesions should be obliterated. However, it is of utmost importance to identify the cases in which total anatomical cure is not possible without worsening the neurological status of the patient. Under such circumstances, an anatomical goal or objective should be defined before starting the treatment. Obliteration of a high-risk portion of the lesion, such as an associated aneurysm, the occlusion of a direct AVF within the nidus, or of a portion draining into a territory with outflow restriction, can result in a favorable long-term outcome.

In our center, treatment options for spinal cord AVMs include excision, endovascular obliteration or partial targeted therapy, or conservative management. If the lesion is deemed suitable for both endovascular and surgical treatment, embolization is first attempted (Fig. 3), often in a staged fashion. Despite the risk of rebleeding, we tend not to treat the lesion during the acute period to avoid interfering with the natural history, given that most patients show some improvement over a couple of months. An exception will be made to exclude a pseudoaneurysm (Fig. 4) or other potentially risky angioarchitecture feature, especially if $>1$ hemorrhage has occurred, but early aggressive intervention is rarely needed.

Endovascular options have evolved significantly since the first report in 1971 by Doppman et al. ${ }^{21}$ of occlusion of spinal cord AVMs. From proximal arterial ligations it 


\section{Spinal cord vascular shunts}

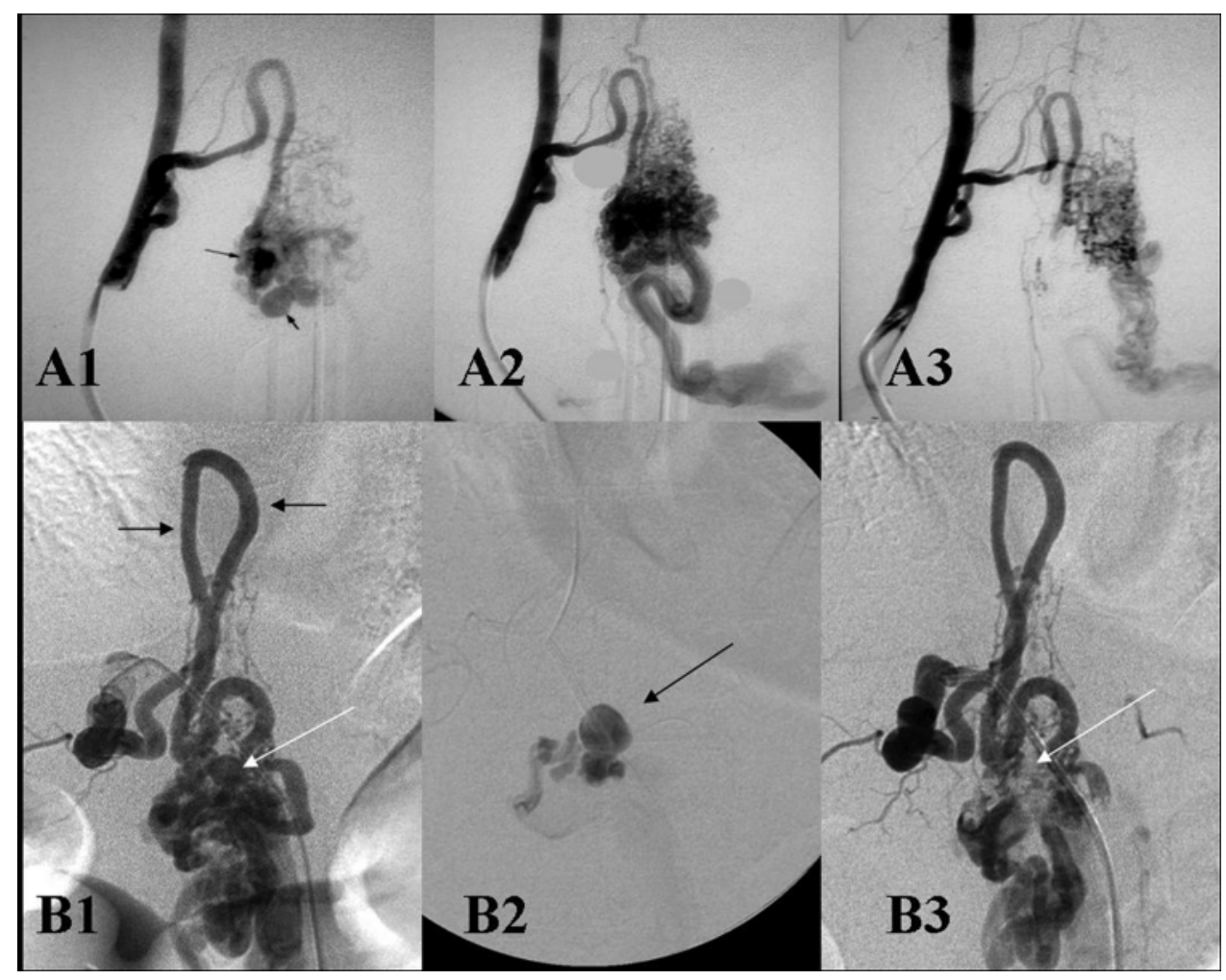

FIG. 4. Upper: Images obtained in a 20-year-old man who presented with 2 episodes of a sudden neurological deficit 3 months apart with incomplete recovery. A vertebral angiogram (early arterial phase) (A1) demonstrating anterior arterial supply of a spinal cord AVM associated with intranidal aneurysms (arrows) likely to be the cause of repeated hemorrhagic episodes. Angiograms prior to (A2) and after (A3) superselective catheterization and embolization with glue (NBCA) of the anterior spinal arterial sulcal-commissural branches containing the aneurysms, demonstrating that aneurysms are no longer being filled as well as reduced flow and size of the residual nidus. No complications occurred, and no further hemorrhage was documented on > 15-year follow-up. Lower: Images obtained in a 40-year-old woman who presented with repeated episodes of SAH. A spinal angiogram (B1) demonstrating a spinal cord AVM at the level of the conus supplied mostly from anterior spinal artery (black arrows) and possible associated intranidal aneurysm (white arrow). Superselective catheterization of the ASA and selective injection (B2) of the sulcal-commissural branch showing the nidal aneurysm (arrow). Postembolization angiogram (B3) with glue (NBCA) into the aneurysm demonstrating elimination of the aneurysm (arrow). No complications occurred, and no further hemorrhages have been documented at the 6-month follow-up.

evolved to superselective injections of permanent embolic material in specific points of the AVM, being able to preserve important blood supply to the cord. In our combined experience of 3 major centers for cerebrovascular disease, outcome measurements after embolization were graded as excellent (normal neurological status or AVM obliteration), good (better or stable neurological status, with $\geq 90 \%$ obliteration), fair (not better or in those with mild worsening), and poor (clearly worse or permanent complication from the procedure). Of 47 treated spinal cord AVMs, outcome was excellent in $49 \%$ of patients and good in $28 \%$; $77 \%$ of the cases had a favorable result. None of the patients with a previous fixed deficit returned to their normal condition. Permanent worsening directly related to the procedure occurred in $11 \%$ of the cases, and transient complications occurred in another $11 \%$. One patient died of ascending myelopathy 15 months after treatment. Immediate complete obliteration of the malformation was achieved in almost half of the patients by embolization alone. In the remaining patients, partial targeted embolization or combined approaches associating embolization and surgery were used. Recurrent hem- orrhage occurred in $4 \%$ patients, all with cervical spinal cord AVMs incompletely treated at the time of rebleeding, while they were waiting for complementary embolization.

Yașargil and colleagues ${ }^{58}$ reported good results in 41 patients with spinal cord AVMs who underwent surgical treatment, although in $73 \%$ of patients no angiographic follow-up was available, despite intraoperative report of complete removal. Clinical improvement occurred in $48 \%$ of the cases and clinical worsening in $19.5 \%$; there was 1 death directly related to surgery. Spetzler et al..$^{51}$ reported on their surgical experience that $68 \%$ of the patients (27 spinal cord AVMs) improved and 29\% remained the same, with $92 \%$ of complete resection. Considering the significant complexity of some approaches to these lesions, which may include anterior and anterolateral spinal approaches and postoperative stabilization, we believe it is justified to consider endovascular treatment as a first choice.

Conservative treatment includes management of the various complications of persistent neurological deficit; physical therapy, pain control management, nursing, and 


\section{Da Costa, A. R. Dehdashti, and K. G. terBrugge}

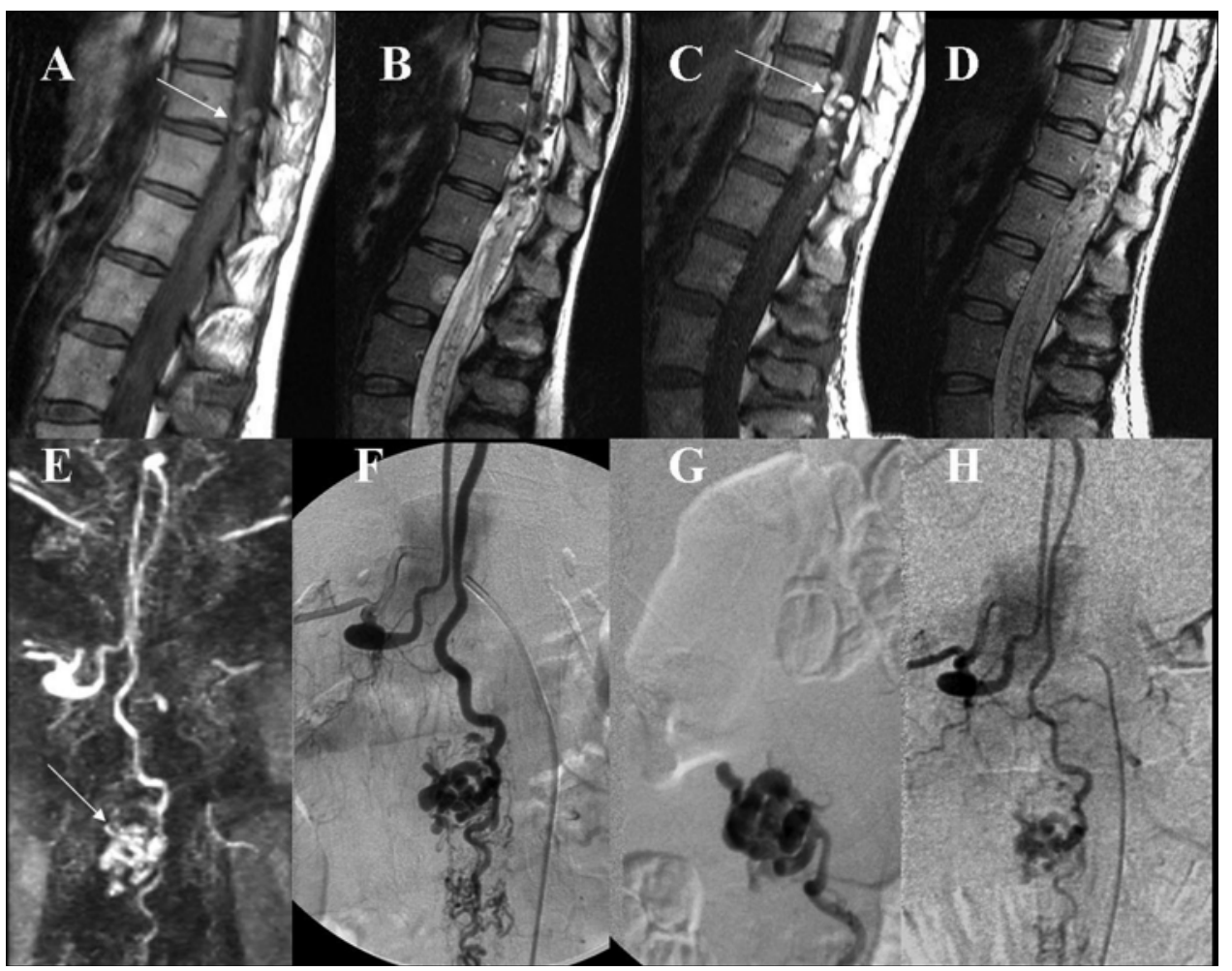

FIG. 5. Images obtained in a 25-year-old woman who presented with subacute progressive neurological deficit. $A$ and $B$ : Sagittal T1- (A) and T2- (B) weighted MR images demonstrating the presence of tubular structures without flow void (arrow in A) in addition to multiple intradural flow voids. C-E: Additional MR images obtained 4 days later, demonstrating increased signal on T1-weighted imaging of these tubular structures (arrow in C) representing venous thrombosis as well as fewer flow voids on T2-weighted imaging (D), whereas contrast-enhanced MR imaging (E) showed the moderate-sized spinal AVM (arrow). Anticoagulation therapy was started. F and G: Angiograms. Progression of neurological symptoms prompted angiography $(F)$ and superselective catheterization of the anterior spinal arterial supply to the nidus, and partial embolization with glue (NBCA) was performed (G). H: Postembolization angiogram showing reduction of flow and size of the spinal AVM. Clinical stabilization and subsequent neurological improvement occurred.

psychotherapy should be included. After hemorrhage has been excluded, anticoagulation with heparin may be indicated in situations in which thrombosis and/or slow flow in the AVM results in worsening venous hypertension of the cord (Fig. 5).

\section{Spinal DAVFs}

As opposed to the spinal cord AVMs, spinal DAVFs are acquired shunts located within or adjacent to the dura along the spinal canal. Anatomically, a spinal DAVF is an abnormal arteriovenous shunt in the dura, which can be located anywhere along the dura but is most commonly situated near the nerve root exit. ${ }^{31,37,48,52}$ The arterial supply usually arises from a dural branch of the dorsospinal artery, draining into a usually single, very dilated, tortuous vein that can pierce the dura quite far from a nerve root, eventually reaching the perimedullary venous system ${ }^{9}$ and producing venous hypertension that leads to a slowly progressive mixed motor and sensory myelopathy that can progress to irreversible myelopathy, ${ }^{3,4,12,37,52}$ The chronic venous hypertension reduces the arteriovenous pressure gradient and decreases tissue perfusion, resulting in progressive hypoxia to the spinal cord, producing intramedullary vasodilation, further decreasing blood flow, with possible exhaustion of autoregulation in the affected areas. This will decrease tissue perfusion and generate edema and progressive loss function.

Spinal DAVFs are the most frequent arteriovenous shunts in older adults, usually presenting after the 4th or 5 th decade of life with a heavy male predominance (5:1). The most frequent location is in the midthoracic spine. A cervical localization is rare, but one should be aware that dural shunts located at the level of the foramen magnum or above can present with spinal cord myelopathy due to spinal cord venous drainage. ${ }^{13,34,55}$ The clinical presentation is characterized by progressive motor and sensory symptoms, with spasticity, paresthesias, pain, bladder, and bowel disturbances, and sexual dysfunction. ${ }^{37,46,48,53}$ Hemorrhage is extremely rare. ${ }^{20} \mathrm{~A}$ lag between initial symptoms and diagnosis is common, on average 10.5 months in our series. ${ }^{53}$

In a recent paper, Geibprasert et al. ${ }^{24}$ made an important contribution to our understanding of these fistulas. These authors were able to connect cranial and spinal DAVFs based on embryological and developmental aspects of the venous drainage of the central nervous system, classifying them according to their venous drainage into ventral epidural, dorsal epidural, and lateral epidural, 

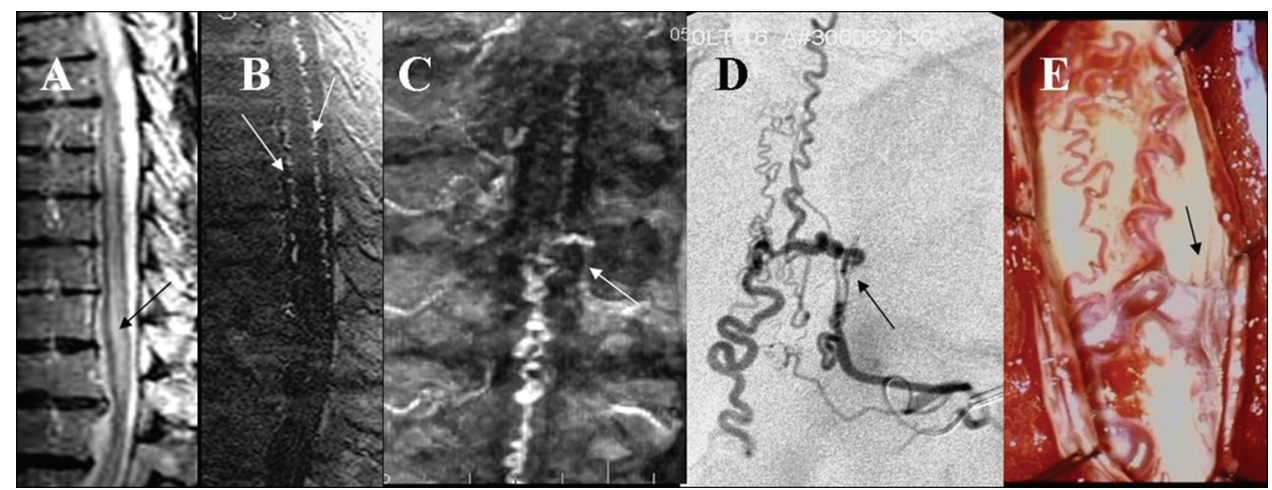

FIG. 6. Images obtained in a 76-year-old man with a slowly progressive neurological deficit over several months. A T2-weighted MR image (A) demonstrating increased signal within the cord (arrow). Contrast-enhanced sagittal MR image (B) showing early filling of the perimedullary venous system (arrows), whereas a 3D reconstructed coronal view (C) demonstrates the likely level of the dural shunt (arrow), confirmed at spinal angiography (D) and at surgery (E) when the enlarged radicular vein (arrow) was clipped and disconnected.

generating 3 groups with very different demographics, presentation, and outcomes. As they pointed out in their paper, the decision to treat is still based on the presence of venous reflux into cortical or perimedullary veins, but as with spinal cord AVMs, grouping these lesions based solely on anatomical and angiographic characteristics ignores very important differences and hinders the advancement of our understanding.

Magnetic resonance imaging is the initial investigative modality of choice, usually showing signal changes within the cord, no mass effect, and nonspecific slight enhancement with Gd, suggesting a nonneoplastic or nondemyelinating cause of the symptoms..$^{25,35}$ The identification of abnormal perimedullary flow voids points to a vascular abnormality. These findings on MR imaging are nonspecific, and spinal angiography is necessary to confirm the diagnosis and establish the exact location of the nidus and the point at which the vein pierces the dura reaching the intradural space. Improvements in MR imaging technique ${ }^{22}$ now allow the establishment of an area of interest and help to focus spinal angiography at a

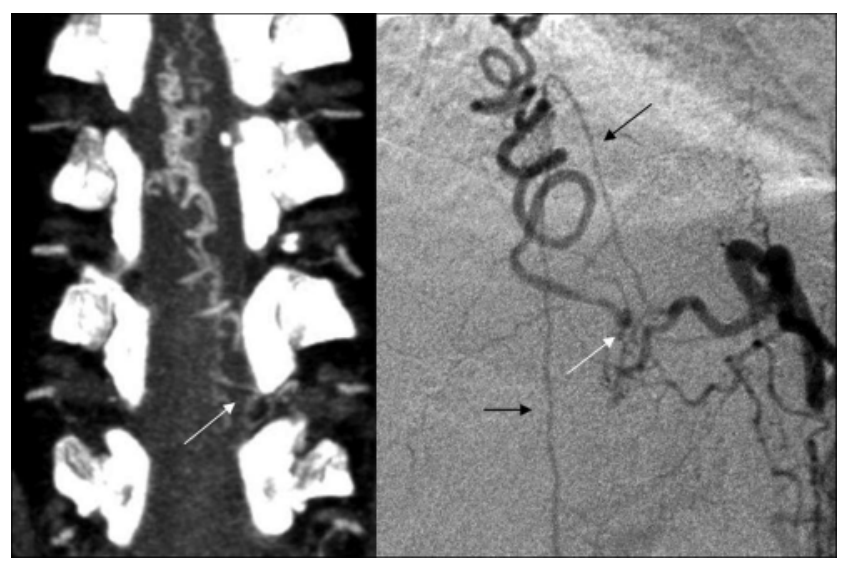

FIG. 7. Images obtained in an 80-year-old man with a slowly progressive neurological deficit. Coronal CT angiography view (left) identifies the probable level of the DAVF (arrow). An angiogram (right) demonstrating the radiculomedullary artery (ASA, black arrows) arising from the same radicular artery as the dural shunt (white arrow) precluding safe endovascular treatment. specific segmental level (Fig. 6). During angiography, it is important to assess the blood supply to the spinal cord, particularly the origin of the ASA. The origin of the ASA can be located at the same level as the radicular supply to the dural fistula, a contraindication for endovascular treatment (Fig. 7). ${ }^{2}$ Bimetameric supply (a location of the shunt in the dura between 2 adjacent nerve roots resulting in dual arterial supply) can occur in a percentage of cases, with important implications for treatment and postembolization angiographic control.

Considering that endovascular and surgical treatments have low risk and good results as well as the known natural history of a progressive neurological deficit if untreated, we favor treatment for virtually all spinal DAVFs, with the goal of occluding the draining vein as it exits the dura, disconnecting the fistula from the spinal cord venous system. An attempt at endovascular treatment is always performed as a first treatment choice, usually at the time of diagnostic angiography, done after induction of general anesthesia. A permanent, low-viscosity liquid adhesive agent, NBCA, is used when attempting to reach the nidus and the proximal vein. Particulate agents, such as polyvinyl alcohol or Gelfoam are contraindicated because of very high recanalization and recurrence rates..$^{27,38}$ The fistula is considered treated only if NBCA reaches and occludes the proximal portion of the draining vein. Our initial success rate with endovascular occlusion of spinal DAVFs is $25 \%$, with no evidence of recanalization. ${ }^{53}$ Complications are rare and are usually associated with the failure to recognize a common origin for the spinal DAVF supply and the anterior or posterior spinal arterial systems or inadvertent deposition of the embolic material beyond the nidal-venous junction, reaching the perimedullary venous system.

If endovascular therapy is unsuccessful, surgery is indicated. We usually perform the surgical disconnection during the same hospital stay. Although in the past excision of the dura at the site of fistula was proposed, ${ }^{38,52}$ we, as most groups, treat spinal DAVFs by simple venous disconnection..$^{1,40,53}$ Outcomes are usually good, with the majority of patients showing clinical improvement or at least stabilization of symptoms after interruption of the 
abnormal venous drainage. The best results are seen in patients treated soon after onset of symptoms. Motor and deep sensory symptoms are more likely to improve than superficial sensation and sphincter disturbances. , $^{8,36,50,53}$ Patients submitted to surgical disconnection should have a postoperative angiogram confirming the interruption of the intradural venous drainage before leaving the hospital. If there is no clinical improvement or recurrent symptoms occur, additional MR imaging and angiography is advised. It is important to remember that signal changes within the cord can persist for a while even in patients with clinical improvement. ${ }^{56}$ Therefore, absence of improvement on MR imaging does not necessarily reflect residual or recurrent spinal DAVF.

Although multiplicity of spinal dural arteriovenous shunts is extremely rare as is the metachronous occurrence of such lesions, ${ }^{33}$ any development of new or worsening neurological deficit should warrant additional investigation with MR imaging to exclude such diagnosis or to exclude venous thrombosis.

\section{Conclusions}

Spinal arteriovenous shunt is a broad term that encompasses many entities, from true arteriovenous shunts located inside the spinal cord to epidural shunts with venous drainage directed toward the spinal canal. Even within similar locations, important differentiation should be made. Spinal cord AVMs in a patient with a systemic disease such as hereditary hemorrhage telangiectasia are clearly different from sporadic spinal cord AVMs. Management should be based on the idea that preservation of function is the goal, not complete radiological cure, and understanding the basic aspects of the disease will help to differentiate between patients in whom treatment is advised and patients in whom only more harm can be done. We favor classifications that allow us to consider all the aspects involved in each lesion instead of grouping lesions into artificial categories, which, as demonstrated recently by Geibprasert et al., ${ }^{24}$ can impair our ability to recognize differences that can be crucial for proper management.

\section{Disclaimer}

The authors report no conflict of interest concerning the materials or methods used in this study or the findings specified in this paper.

\section{References}

1. Afshar JK, Doppman JL, Oldfield EH: Surgical interruption of intradural draining vein as curative treatment of spinal dural arteriovenous fistulas. J Neurosurg 82:196-200, 1995

2. Aggarwal S, Willinsky R, Montanera W, Terbrugge K, Wallace MC: Superselective angiography of a spinal dural arteriovenous fistula having a common segmental origin with the artery of Adamkiewicz. Neuroradiology 34:352-354, 1992

3. Aminoff MJ, Barnard RO, Logue V: The pathophysiology of spinal vascular malformations. J Neurol Sci 23:255-263, 1974

4. Aminoff MJ, Logue V: The prognosis of patients with spinal vascular malformations. Brain 97:211-218, 1974
5. Aminoff MJ, Logue V: Clinical features of spinal vascular malformations. Brain 97:197-210, 1974

6. Baker HL Jr, Love JG, Layton DD Jr: Angiographic and surgical aspects of spinal cord vascular anomalies. Radiology 88: $1078-1085,1967$

7. Bao YH, Ling F: Classification and therapeutic modalities of spinal vascular malformations in 80 patients 1 . Neurosurgery 40:75-81, 1997

8. Barth MO, Chiras J, Rose M, Vega Molina J, Bories J: [Results of embolization of spinal dural arteriovenous fistulas with perimedullary venous drainage.] Neurochirurgie 30:381-386, 1984 (Fr)

9. Benhaiem N, Poirier J, Hurth M: Arteriovenous fistulae of the meninges draining into the spinal veins. A histological study of 28 cases. Acta Neuropathol 62:103-111, 1983

10. Berenbruch K: Ein fall von multiplen Angio-Lipomen Lombiniert mit einem angiom des Rückenmarks [thesis]. Tubingin, Germany: Universität Tubingen, 1890. Ref Type: Thesis/Dissertation

11. Berenstein A, Lasjaunias P, ter Brugge K: Spinal cord arteriovenous malformations, in Berenstein $\mathrm{A}$, Lasjaunias $\mathrm{P}$, ter Brugge K (eds): Surgical Neuroangiography, Vol 2.2. New York: Springer-Verlag, 2003, pp 737-843

12. Berenstein A, Lasjaunias P, ter Brugge K: Spinal dural arteriovenous fistulas, in Berenstein A, Lasjaunias $\mathrm{P}$, ter Brugge K (eds): Surgical Neuroangiography, Vol 2.2. New York: Springler-Verlag, 2003, pp 849-872

13. Bret P, Salzmann M, Bascoulergue Y, Guyotat J: Dural arteriovenous fistula of the posterior fossa draining into the spinal medullary veins-an unusual cause of myelopathy: case report. Neurosurgery 35:965-968, 1994

14. Cogen P, Stein BM: Spinal cord arteriovenous malformations with significant intramedullary components 1 . J Neurosurg 59:471-478, 1983

15. Di Chiro G, Doppman J, Ommaya AK: Selective arteriography of arteriovenous aneurysms of spinal cord. Radiology 88:1065-1077, 1967

16. Djindjian R: Arteriography of the spinal cord. Am J Roentgenol Radium Ther Nucl Med 107:461-478, 1969

17. Djindjian R, Houdart R, Hurth M: [Angiography of the spinal cord.] Acta Radiol Diagn (Stockh) 9:707-726, 1969 (Fr)

18. Djindjian R, Hurth M, Houdart R: [Selective arteriography of the cervical spinal cord (technic, normal and pathologic arteriography).] Rev Neurol (Paris) 122:321-335, 1970 (Fr)

19. Djindjian R, Merland JJ, Djindjian M, Houdart R: [Embolization in the treatment of medullary arteriovenous malformations in 38 cases (author's transl).] Neuroradiology 16:428429, 1978 (Fr)

20. Do HM, Jensen ME, Cloft HJ, Kallmes DF, Dion JE: Dural arteriovenous fistula of the cervical spine presenting with subarachnoid hemorrhage. AJNR Am J Neuroradiol 20:348350, 1999

21. Doppman JL, Di CG, Ommaya AK: Percutaneous embolization of spinal cord arteriovenous malformations. J Neurosurg 34:48-55, 1971

22. Farb RI, Kim JK, Willinsky RA, Montanera WJ, ter Brugge $\mathrm{K}$, Berbyshire JA, et al: Spinal dural arteriovenous fistula localization with a technique of first-pass gadolinium-enhanced MR angiography: initial experience. Radiology 222:843-850, 2002

23. Gaupp J: Casuistische Beiträge zur pathologischen Anatomie des Rückenmarks und seiner Häute. Beitr Pathol Anat 2:510-524, 1888

24. Geibprasert S, Pereira V, Krings T, Jiarakongmun P, Toulgoat F, Pongpech S, et al: Dural arteriovenous shunts: a new classification of craniospinal epidural venous anatomical bases and clinical correlations. Stroke 10:2783-2794, 2008

25. Gilbertson JR, Miller GM, Goldman MS, Marsh WR: Spinal 
dural arteriovenous fistulas: MR and myelographic findings. AJNR Am J Neuroradiol 16:2049-2057, 1995

26. Grote EH, Voigt K: Clinical syndromes, natural history, and pathophysiology of vascular lesions of the spinal cord 1 . Neurosurg Clin N Am 10:17-45, 1999

27. Hall WA, Oldfield EH, Doppman JL: Recanalization of spinal arteriovenous malformations following embolization. J Neurosurg 70:714-720, 1989

28. Heboldt O: Aneurysmen der kleinsten Rückenmarksge. Arch Psychiatr Nervenkr 16:813-817, 1885

29. Heros RC, Debrun GM, Ojemann RG, Lasjaunias PL, Naessens PJ: Direct spinal arteriovenous fistula: a new type of spinal AVM. Case report 20. J Neurosurg 64:134-139, 1986

30. Houdart R, Djindjian R: Angiomas of the spinal cord. Proc R Soc Med 59:787-790, 1966

31. Kendall BE, Logue V: Spinal epidural angiomatous malformations draining into intrathecal veins. Neuroradiology 13:181-189, 1977

32. Krause F: Surgery of the Brain and Spinal Cord: Based on Personal Experiences, Vol 2. New York: Rebman Company, 1912 Ref Type: Thesis/Dissertation

33. Ling J, Agid R, Nakano S, Souza MPS, Reintamm G, terBrugge KG, et al: Metachronous multiplicity of spinal cord arteriovenous fistula and spinal dural AVF in a patient with hereditary hemorrhagic telangiectasia. Interventional Neuroradiology 11:79-82, 2005

34. Mahagne MH, Rogopoulos A, Paquis P, Guilhem D, Lonjon M, Grellier P, et al: [Intracranial dural arteriovenous fistula with spinal venous drainage.] Rev Neurol (Paris) 148:789792, $1992(\mathrm{Fr})$

35. Masaryk TJ, Ross JS, Modic MT, Ruff RL, Selman WR, Ratcheson RA: Radiculomeningeal vascular malformations of the spine: MR imaging. Radiology 164:845-849, 1987

36. Merland JJ, Laurent A, Khayata MH Casasco A, Aymad A, Gobin P: Embolization of spinal vascular lesions, in Vinuela F, Dion JE (eds): Interventional Neuroradiology: Endovascular Therapy of the Central Nervous System. New York: Raven Press, 1992, pp 153-165

37. Merland JJ, Riche MC, Chiras J: Intraspinal extramedullary arteriovenous fistulae draining into the medullary veins. J Neuroradiol 7:271-320, 1980

38. Morgan MK, Marsh WR: Management of spinal dural arteriovenous malformations. J Neurosurg 70:832-836, 1989

39. Newman MJ: Racemose angioma of the spinal cord. Q J Med 28:97-108, 1959

40. Oldfield EH, Di CG, Quindlen EA, Rieth KG, Doppman JL: Successful treatment of a group of spinal cord arteriovenous malformations by interruption of dural fistula. J Neurosurg 59:1019-1030, 1983

41. Pia HW, Vogelsang H: [Diagnosis and therapy of spinal angioma.] Dtsch Z Nervenheilkd 187:74-96, 1965 (Ger)

42. Riche MC, Reizine D, Melki JP, Merland JJ: Classification of spinal cord vascular malformations. Radiat Med 3:17-24, 1985

43. Rodesch G, Hurth M, Alvarez H, David P, Tadie M, Lasjaunias P: Embolization of spinal cord arteriovenous shunts: morphological and clinical follow-up and results-review of 69 consecutive cases 12 . Neurosurgery 53:40-49, 2003

44. Rodesch G, Hurth M, Alvarez H, Ducot B, Tadie M,Lasjaunias P: Angio-architecture of spinal cord arteriovenous shunts at presentation. Clinical correlations in adults and children. The Bicetre experience on 155 consecutive patients seen between 1981-1999. Acta Neurochir (Wien) 146:217-226, 2004

45. Rodesch G, Hurth M, Alvarez H, Tadie M, Lasjaunias P: Classification of spinal cord arteriovenous shunts: proposal for a reappraisal-the Bicetre experience with 155 consecutive patients treated between 1981 and 1999. Neurosurgery 51:374-379, 2002

46. Rodesch G, Hurth M, Alvarez H, Tadie M, Lasjaunias P: Spinal cord intradural arteriovenous fistulae: anatomic, clinical, and therapeutic considerations in a series of 32 consecutive patients seen between 1981 and 2000 with emphasis on endovascular therapy . Neurosurgery 57:973-983, 2005

47. Rodesch G, Lasjaunias P: Spinal cord arteriovenous shunts: from imaging to management 13. Eur J Radiol 46:221-232, 2003

48. Rosenblum B, Oldfield EH, Doppman JL, Di Chiro G: Spinal arteriovenous malformations: a comparison of dural arteriovenous fistulas and intradural AVM's in 81 patients 1 . J Neurosurg 67:795-802, 1987

49. Scarff TB, Reigel DH: Arteriovenous malformations of the spinal cord in children. Childs Brain 5:341-351, 1979

50. Song JK, Gobin YP, Duckwiler GR, Murayama Y, Frazee JG, Martin NA, et al: N-butyl 2-cyanoacrylate embolization of spinal dural arteriovenous fistulae. AJNR Am J Neuroradiol 22:40-47, 2001

51. Spetzler RF, Detwiler PW, Riina HA, Porter RW: Modified classification of spinal cord vascular lesions. J Neurosurg 96:145-156, 2002

52. Symon L, Kuyama H, Kendall B: Dural arteriovenous malformations of the spine. Clinical features and surgical results in 55 cases. J Neurosurg 60:238-247, 1984

53. van Dijk JM, TerBrugge KG, Willinsky RA,Farb RI, Wallace MC: Multidisciplinary management of spinal dural arteriovenous fistulas: clinical presentation and long-term follow-up in 49 patients. Stroke 33:1578-1583, 2002

54. Vogelsang H, Pia HW: [Importance of spinal angiography for the diagnosis of spinal angioma.] Fortschr Geb Rontgenstr Nuklearmed 102:661-666, 1965 (Ger)

55. Willinsky R, Terbrugge K, Lasjaunias P, Montanera W: The variable presentations of craniocervical and cervical dural arteriovenous malformations. Surg Neurol 34:118-123, 1990

56. Willinsky RA, Terbrugge K, Montanera W, Mikulis D, Wallace MC, et al: Posttreatment MR findings in spinal dural arteriovenous malformations. AJNR Am J Neuroradiol 16:2063-2071, 1995

57. Wyburn-Mason R: The Vascular Abnormalities and Tumours of the Spinal Cord and Its Membranes. London: Kimpton, 1943

58. Yașargil MG, Symon L, Teddy PJ: Arteriovenous malformations of the spinal cord. Adv Tech Stand Neurosurg 11:61102,1984

Manuscript submitted July 10, 2008.

Accepted October 22, 2008.

Address correspondence to: Karel G. terBrugge, M.D., Division of Neuroradiology, University of Toronto and University Health Network, 399 Bathurst Street-Fell Pavilion 3-210 Toronto, Ontario, Canada M5T 2S8. email: karel.terbrugge@uhn.on.ca. 